\title{
Understanding the quality of life (QOL) issues in survivors of cancer: towards the development of an EORTC QOL cancer survivorship questionnaire
}

Marieke van Leeuwen ${ }^{1 *}$ D , Olga Husson ${ }^{2}$, Paola Alberti ${ }^{3,4}$, Juan Ignacio Arraras ${ }^{5}$, Olivier L. Chinot ${ }^{6}$, Anna Costantini ${ }^{7}$, Anne-Sophie Darlington ${ }^{8}$, Linda Dirven ${ }^{9,10}$, Martin Eichler ${ }^{11}$, Eva B. Hammerlid ${ }^{12}$, Bernhard Holzner ${ }^{13}$,

Colin D. Johnson ${ }^{14}$, Meropi Kontogianni ${ }^{15}$, Trille Kristina Kjær ${ }^{16}$, Ofir Morag ${ }^{17}$, Sandra Nolte ${ }^{18}$, Andrew Nordin ${ }^{19}$, Andrea Pace ${ }^{20}$, Monica Pinto ${ }^{21}$, Katja Polz ${ }^{22}$, John Ramage ${ }^{23}$, Jaap C. Reijneveld ${ }^{24}$, Samantha Serpentini ${ }^{25}$, Krzysztof A. Tomaszewski ${ }^{26}$, Vassilios Vassiliou ${ }^{27}$, Irma M. Verdonck-de Leeuw ${ }^{28}$, Ingvild Vistad ${ }^{29}$, Teresa E. Young ${ }^{30}$, Neil K. Aaronson ${ }^{1}$, Lonneke V. van de Poll-Franse ${ }^{1,31,32}$ and on behalf of the EORTC QLG

\begin{abstract}
Backround: The number of cancer survivors is growing steadily and increasingly, clinical trials are being designed to include long-term follow-up to assess not only survival, but also late effects and health-related quality of life (HRQOL). Therefore it is is essential to develop patient-reported outcome measures (PROMs) that capture the full range of issues relevant to disease-free cancer survivors. The objectives of this project are: 1) to develop a European Organisation for Research and Treatment of Cancer (EORTC) questionnaire that captures the full range of physical, mental and social HRQOL issues relevant to disease-free cancer survivors; and 2) to determine at which minimal time since completion of treatment the questionnaire should be used.
\end{abstract}

Methods: We reviewed 134 publications on cancer survivorship and interviewed 117 disease-free cancer survivors with 11 different types of cancer across 14 countries in Europe to generate an exhaustive, provisional list of HRQOL issues relevant to cancer survivors. The resulting issue list, the EORTC core questionnaire (QLQ-C30), and site-specific questionnaire modules were completed by a second group of 458 survivors.

Results: We identified 116 generic survivorship issues. These issues covered body image, cognitive functioning, health behaviors, negative and positive outlook, health distress, mental health, fatique, sleep problems, physical functioning, pain, several physical symptoms, social functioning, and sexual problems. Patients rated most of the acute symptoms of cancer and its treatment (e.g. nausea) as no longer relevant approximately one year after completion of treatment.

Conclusions: Compared to existing cancer survivorship questionnaires, our findings underscore the relevance of assessing issues related to chronic physical side effects of treatment such as neuropathy and joint pain. We will further develop a core survivorship questionnaire and three site-specific modules for disease-free adult cancer survivors who are at least one year post-treatment.

Keywords: Cancer survivor, Disease-free, Health- related quality of life, Survivorship questionnaire, Disease-free, Oncology

\footnotetext{
* Correspondence: m.v.leeuwen@nki.nl

${ }^{1}$ Division of Psychosocial Research \& Epidemiology, The Netherlands Cancer

Institute, Amsterdam, The Netherlands

Full list of author information is available at the end of the article
}

(c) The Author(s). 2018 Open Access This article is distributed under the terms of the Creative Commons Attribution 4.0 International License (http://creativecommons.org/licenses/by/4.0/), which permits unrestricted use, distribution, and reproduction in any medium, provided you give appropriate credit to the original author(s) and the source, provide a link to the Creative Commons license, and indicate if changes were made. The Creative Commons Public Domain Dedication waiver (http://creativecommons.org/publicdomain/zero/1.0/) applies to the data made available in this article, unless otherwise stated. 


\section{Background}

With continuing improvement in early detection and treatment, and an aging population, the number of cancer survivors is increasing steadily. This has resulted in a growing interest in evaluating the health-related quality of life (HRQOL) of cancer survivors [1]. Increasingly, clinical trials and comparative effectiveness studies are being designed to include long-term follow-up to assess, in addition to survival, late effects of treatment and HRQOL. In order to integrate HRQOL in such studies, it is essential to develop patient-reported outcome measures (PROMs) that capture the full range of issues relevant to disease-free cancer survivors.

Many of the cancer-related HRQOL questionnaires that are available today, including the European Organisation for Research and Treatment of Cancer core questionnaire (EORTC QLQ-C30) [2] and the Functional Assessment of Cancer Therapy - General (FACT-G) [3], with their supplementary site-specific modules, may not be entirely appropriate for assessing the experiences of disease-free cancer survivors. These questionnaires include items assessing acute and treatment-related symptoms (e.g., vomiting) that are typically no longer relevant in the post-treatment survivorship period. Conversely, they may not adequately address physical and psychosocial health problems particularly relevant to cancer survivors (e.g., fear of recurrence, return to work).

Questionnaires that have been developed specifically for use among (long-term) cancer survivors include the Cancer Problems in Living Scale (CPILS) [4, 5], Impact of Cancer (IOC/IOCv2) [6-8], Quality of Life in Adult Cancer Survivors (QLACS) [9, 10], Quality of Life Cancer Survivors (QoL-CS) [11] and Satisfaction with Life Domains Scale for Cancer (SLDS-C) [12]. These questionnaires focus primarily on psychosocial aspects of survivorship and pay relatively little attention to assessing chronic physical effects of cancer and its treatment [13]. Additionally, while they assess generic (e.g., fear of recurrence) HRQOL issues relevant to the survivorship period, these questionnaires do not include conditionspecific issues which may persist or arise as a long-term consequence of treatment (e.g., genitourinary problems in prostate cancer survivors or lymphedema problems in breast cancer survivors). Also, they often have been based on investigations of a limited number of cancer sites and on survivors living in the United States [4-8, 12], thus limiting their generalizability to other survivor populations in other countries. Finally, for most of these questionnaires, there is only limited information available about their psychometric properties, or the psychometrics have been based on only a small number of cancer survivor populations [13].

For this reason, the EORTC Quality of Life Group (QLG) has embarked on a project with the primary objective of developing a HRQOL assessment approach that captures the full range of issues relevant to diseasefree cancer survivors, both in general and for specific cancer sites. Many definitions of cancer survivorship have been used in the literature [14]. We use the term "cancer survivor" to describe any person who has been diagnosed with cancer who has completed treatment with curative-intent (with the exception of maintenance treatment) and is disease-free (no evidence of active cancer). Since The EORTC QLG's current portfolio of measures has been primarily designed to assess patients' HRQOL during treatment and shortly after completion of treatment, it makes sense to begin use of survivorship measures once the acute symptoms of the disease and its treatment have resolved. An important secondary objective of this project is to determine the most appropriate minimum time since end of primary treatment for commencing use of survivorship HRQOL measures.

The conceptual framework we employed for the development of the questionnaire followed the World Health Organization (WHO) definition of health, dating from 1948, as "a state of complete physical, mental, and social well-being and not merely the absence of disease or infirmity". Combined with the Medical Outcomes study (MOS) framework it delineates three key dimensions of health: physical, mental and social [15]. These three dimensions can be assessed by several types of indicators (see Fig. 1). Some of these indicators reflect primarily one of the three dimensions (e.g., physical functioning) and others reflect two or three dimensions (e.g., fatigue) [15].

In terms of measurement strategy, this project follows the tradition within the EORTC QLG of involving patients from a range of countries, cultures and languages at every step in the developmental process. Additionally, given the goal of addressing both generic and cancer site-specific survivorship issues, the project encompasses a broad range of diagnostic groups. We follow the EORTC QLG's four- phase process of questionnaire development [16]: 1) generation of relevant HRQOL of issues; 2) conversion of HRQOL issues into a set of questionnaire items; 3) questionnaire pre-testing; and 4) large-scale international field testing. In the current paper we report on the results of the first phase of this project.

\section{Methods}

Phase I had two aims: 1) to determine the full range of issues relevant to disease-free cancer survivors, both in general and for specific cancer sites; and 2) to determine the most appropriate minimum time since end of primary treatment for commencing use of survivorship HRQOL measures. It consisted of two sub-phases: In phase 1a we generated an exhaustive list of HRQOL issues, drawing upon two primary sources: the literature and cancer survivors. In phase $1 \mathrm{~b}$ we asked a sample of 


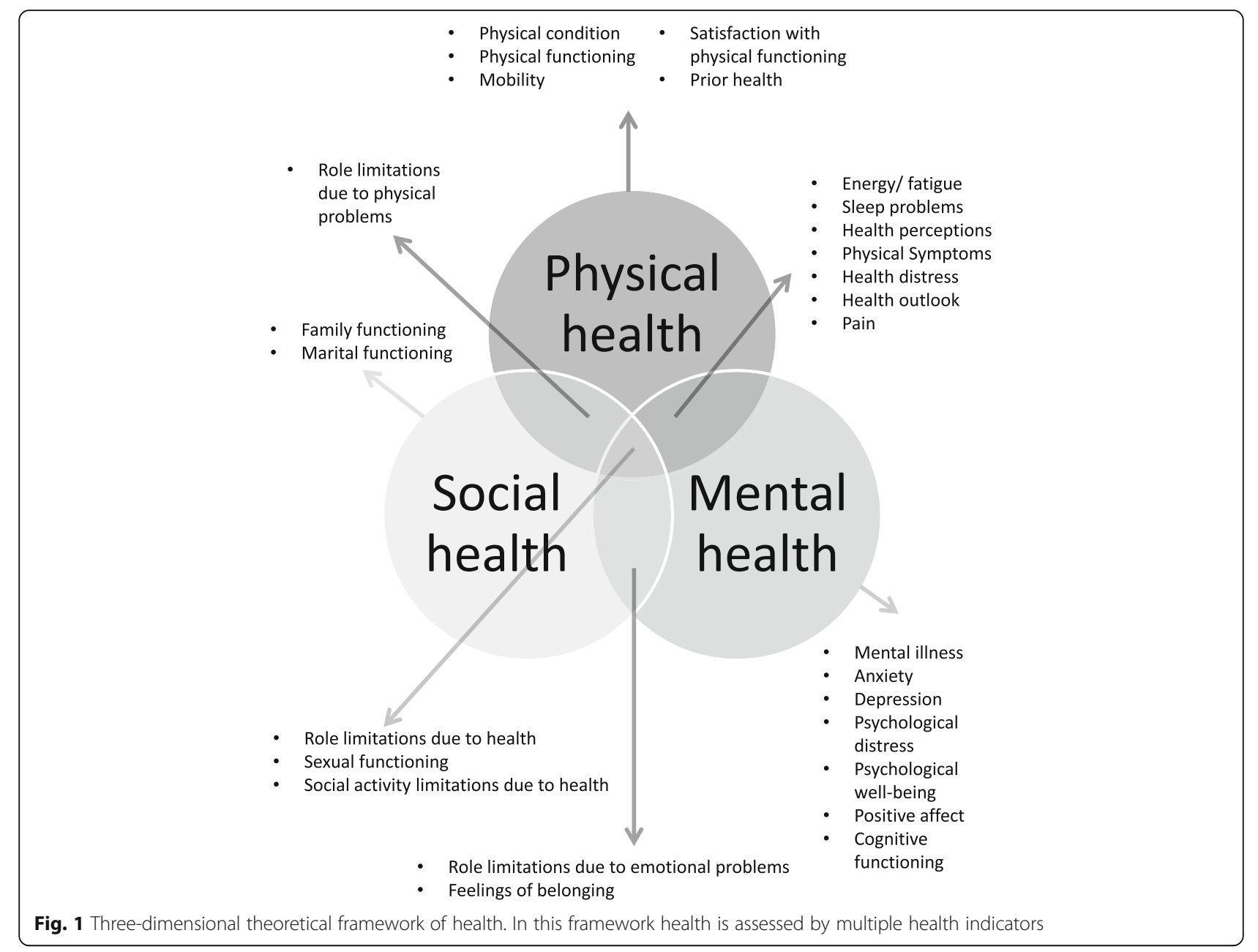

cancer survivors to rate the QLQ-C30 to determine at which time after treatment completion the acute symptoms and side-effects related to cancer and its treatment are no longer relevant. We considered the diminishing prevalence of these symptoms an indicative of the need to shift to the assessment of longer term survivorship issues. In addition, the survivors participating in phase $1 \mathrm{~b}$ rated the list of HRQOL issues developed in phase 1a to identify the issues relevant to disease free-survivors. In this phase only quantitative data analyses were applied. The workflow of the study is also presented in Fig. 2.

\section{Literature search}

In October 2014, we performed a literature search in PubMed and PsycINFO, the goal of which was to identify the full range of HRQOL issues relevant to all adult diseasefree cancer survivors, irrespective of their specific diagnosis. We used the following search terms: ("Survivors"[Major] OR "Survivors/psychology"[Major]) AND ("neoplasms"[Major] OR "Carcinoma"[Major]) AND ("Quality of Life"[Mesh] OR "patient-reported outcomes" OR "health-related quality of life" OR "wellbeing" OR "well-being" OR "Mental
Health"[Major] OR "Physical Fitness/psychology"[Major] OR "Physical Fitness/physiology"[Major] OR "Health Status"[Major] OR "late effects") AND adults. We included only original articles published in English that investigated HRQOL in adult, disease-free cancer survivors. Articles reporting only scale scores without reference to specific survivorship issues were excluded. Two of the authors (MVL and $\mathrm{OH}$ ) screened references independently, and disagreements were resolved by consensus.

\section{Study sample}

For phase 1a \& b we recruited cancer survivors from hospitals from four geographic regions: the United Kingdom, Northern Europe (Denmark, Germany, the Netherlands, Norway, Sweden), Southern Europe (Cyprus, France, Greece, Israel, Italy, Spain), and Central Europe (Austria, Poland). Inclusion of participants for phase $1 \mathrm{~b}$ took place after completion of phase 1a. Eligible patients were those aged 18 years or older at the time of diagnosis who had sufficient command of their native language and did not have severe psychological or cognitive problems. 


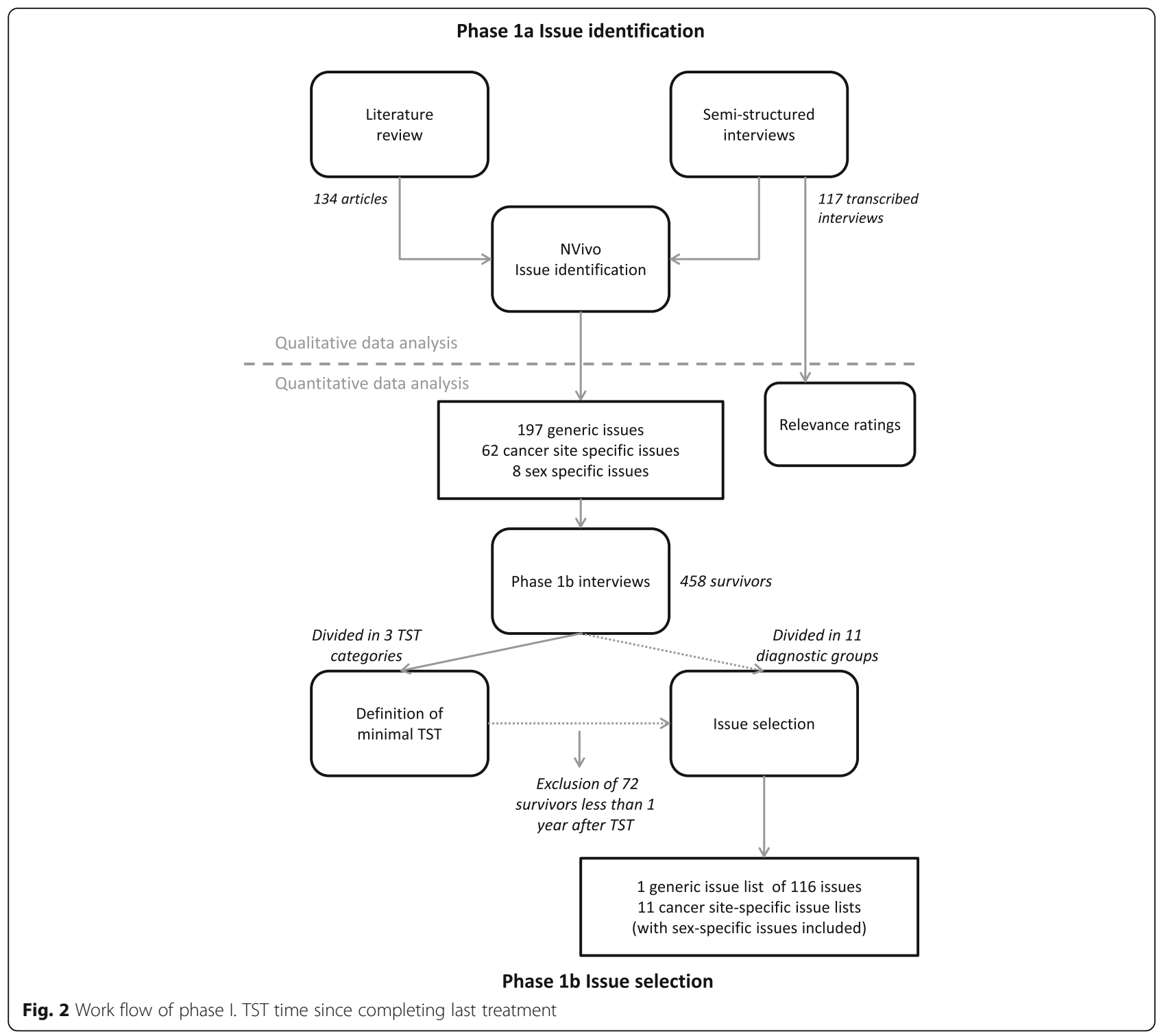

To ensure that the survivorship questionnaire would be generic in nature, we recruited survivors with a range of cancer diagnoses, selected on the basis of their prevalence and/or survival rates. This included 11 diagnoses: breast, colorectal, prostate, bladder, gynecological (ovarian, cervix and endometrial), head and neck, lung, and testicular cancer, lymphoma, melanoma, and glioma. Eligible patients had completed their treatment with curative intent (both primary treatment and treatment of recurrent disease) at least 6 months earlier and were disease-free (no evidence of disease). They could be receiving maintenance therapies (e.g., hormonal treatment for primary breast cancer). Although low-grade glioma patients are not treated with curative intent and are not disease-free, they were included in the study because they have a median survival of between 4.7 and 9.8 years [17]. We employed purposive sampling to ensure an approximately equal distribution of patients across diagnoses and time since treatment (see below).

Basic sociodemographic data collected at study entry included: age, sex, education, employment status, and living arrangement. Clinical data collected included primary diagnosis, stage of disease, type of treatment, date of diagnosis, date of start of primary treatment, date of completing primary treatment, recurrences, date of completion of treatment for last recurrence, and comorbidity using the Charlson Index [18].

\section{Phase 1a survivor interviews: issue generation}

We conducted semi-structured interviews with an initial sample of survivors in order to generate an exhaustive list of relevant HRQOL issues. The goal was to complete 10 interviews per diagnostic group, equally distributed over the four geographical regions [16]. First, the 
respondents were asked open-ended questions about their survivorship experience. Subsequently, respondents were shown the EORTC core questionnaire (QLQ-C30) and, if available, the relevant site-specific questionnaire module [19-32]. These cancer site-specific modules assess the HRQOL issues most relevant to each of the specific patient populations. These modules range in length from 13 to 35 items. Instead of completing these questionnaires, the respondents were asked to rate the relevance of the items on a 4-point scale (not at all, a little bit, quite a bit, or very relevant). The respondents were also asked to identify survivorship issues that they believed to be important that were not included in the QLQ-C30 and, where relevant, site-specific module.

\section{Relevance ratings of the EORTC core questionnaire (QLQ-C30)}

We evaluated the relevance ratings by composing scales that were in accordance with the QLQ-C30 scale structure: 5 multi-item functioning scales (physical, role, emotional, cognitive, and social functioning), three multiitem symptom scales (fatigue, pain, nausea/vomiting), and 6 single items (dyspnea, insomnia, appetite loss, constipation, diarrhea, and financial difficulties). All scores were linearly transformed to a 0 to 100 -points scale. A higher score on a scale means that the survivors considered the items of this particular scale more relevant. We compared the following survivor groups: 0.5 to 2 years since diagnosis, 2 to 5 years since diagnosis, and 5 years or more since diagnosis.

\section{Issue extraction from literature and interviews}

Phase 1a interviews were transcribed and translated in English by the interviewers. We employed thematic analysis [33] using NVivo 10 [34], a software program for qualitative data analyses, to extract a list of relevant survivorship issues from the articles included in the literature review and from the transcribed semi-structured phase 1a interviews. Literature and interviews were analyzed simultaneously using the coding system that evolved during the thematic analyses. Items of the existing questionnaires and the issues described in the qualitative studies were coded in issues that were organized into hierarchical trees. Cancer site or sex-specific issues were extracted in separate coding trees, and kept separately to avoid survivors in phase $1 \mathrm{~b}$ having to rate too many issues. All issues were consolidated into a provisional list which included generic, site-specific, and sex-specific issues to be completed by a second group of survivors in phase $1 \mathrm{~b}$.

Phase $1 \mathrm{~b}$ survivor interviews: defining minimal time since treatment completion and issue selection

In the second round of interviews, our goal was to recruit 330 survivors: 10 interviews per survivor group * 11 diagnostic groups * 3 time periods ( 6 months -2 years / $2-5$ years $/>5$ years since completing primary treatment) [16]. The sample was also stratified according to geographical region. The respondents were asked to complete the provisional issue lists, using a 4-point response scale (not at all, a little bit, quite a bit, or very much) to indicate the extent to which they had experienced each issue. The provisional issue lists consisted of a generic survivor issue list, and the sex- and cancer site-specific issues. In addition, they were also asked to complete the QLQ-C30 and, if available, the relevant site-specific module using the same response scale. This was followed by a debriefing interview about any relevant issues missing from the provisional issue lists.

\section{Definition of the minimal time since end of treatment for assessing survivorship issues}

To determine the minimum time since end of treatment for which the survivorship questionnaire would be relevant, we divided the Phase $1 \mathrm{~b}$ sample into three timesince-completion-of-last-treatment (TST) groups: (1) 0.5 to 1 years; (2) 1 to 2 years; and (3) 2 years or more since treatment completion. For each TST group we investigated which items of the QLQ-C30 were rated as relevant for that specific group: an item was considered relevant if at least $30 \%$ of the respondents in a group endorsed an item (i.e., had experienced the issue at least "a little bit"). We were particularly interested in comparing responses to the QLQ-C30 items between the three TST groups, as the QLQ-C30 contains a number of acute symptom and side-effect items. Our objective here was to determine at what point in time these relatively acute issues were no longer relevant for the majority of respondents, and thus it would be appropriate to begin using survivorship measures.

\section{Criteria for issue selection in phase 16}

In this phase, the provisional issue list was reviewed to generate one comprehensive list of generic issues that was relevant to all groups of cancer survivors, regardless of specific diagnosis. In addition, site-specific issue lists and sex-specific issues were generated. As indicated above, we coded an issue as being endorsed by a respondent if it was scored "a little bit" or higher. An issue needed to be endorsed by at least $30 \%$ of the survivors in any given diagnostic group to be regarded as an issue relevant to that group. If an issue was endorsed by survivors from 6 or more diagnostic groups, it was then considered to be a generic survivorship issue; otherwise it was deemed to be a cancer-site specific issue. This resulted in 12 consolidated survivorship issue lists: one generic list and 11 cancer-site specific lists. 


\section{Sub-analyses in the younger age groups}

Previous research has shown that younger adult survivors can be particularly impacted by the cancer experience [35-41]. For this reason, we performed post-hoc, age-related subgroup analyses to identify issues that are particularly relevant to survivors younger than 50 years. We divided the total sample into five age groups $(<40$; $40-50 ; 50-60 ; 60-70 ; 70+$ years). Issues endorsed as relevant by at least $30 \%$ of respondents under the age of 50 years that would otherwise have been excluded on the basis of ratings by respondents above the age of 50 (i.e. low endorsement in the older sample causing the endorsement in the total sample to be below $30 \%$ ) were retained in the generic list as being particularly relevant for younger cancer survivors. Our expectation was that we would retain issues likely to be specifically relevant to younger cancer survivors such as problems in obtaining a mortgage or family planning.

\section{Results}

Literature review

The literature search identified 1494 publications, of which 134 were retained for issue extraction (for details see Fig. 3). The list of 134 articles included in the review can be found in Additional file 1. Research articles included in the review were most commonly qualitative studies, studies developing cancer survivor specific measures, or studies reporting the use of a self-constructed study-specific measure.

\section{Semi-structured interviews phase 1a: issue generation}

For phase 1a, 117 survivors were interviewed between August 2014 and May 2015 in nine different European countries (Table 1). The average age of the survivors was 57 years $(S D=13.6$ years), and $54 \%$ had received their cancer diagnosis between 2 and 5 years ago.

\section{Issue extraction from literature and interviews}

In the first step, we identified 1555 issues from the 117 interviews and the first $75 \%$ of the research articles. These issues were classified into 11 themes: mental health, physical symptoms, cognitive changes, role functioning (including work), meaning of cancer, health behaviors, spirituality, social functioning (including feelings of belonging), financial issues, body image, and sexuality. In the next step we reduced this list to 718 issues by combining issues that were very similar or formed a continuous scale (e.g. "depression" and "feeling depressed" were combined into "feeling depressed"). The remaining $25 \%$ of studies was coded using this 718 issues coding system. We did not identify new issues in these studies. In the last step, the total number of issues was further reduced. Issues that were very specific were combined. For example, "fear of recurrence when having physical symptoms" and "fear of recurrence

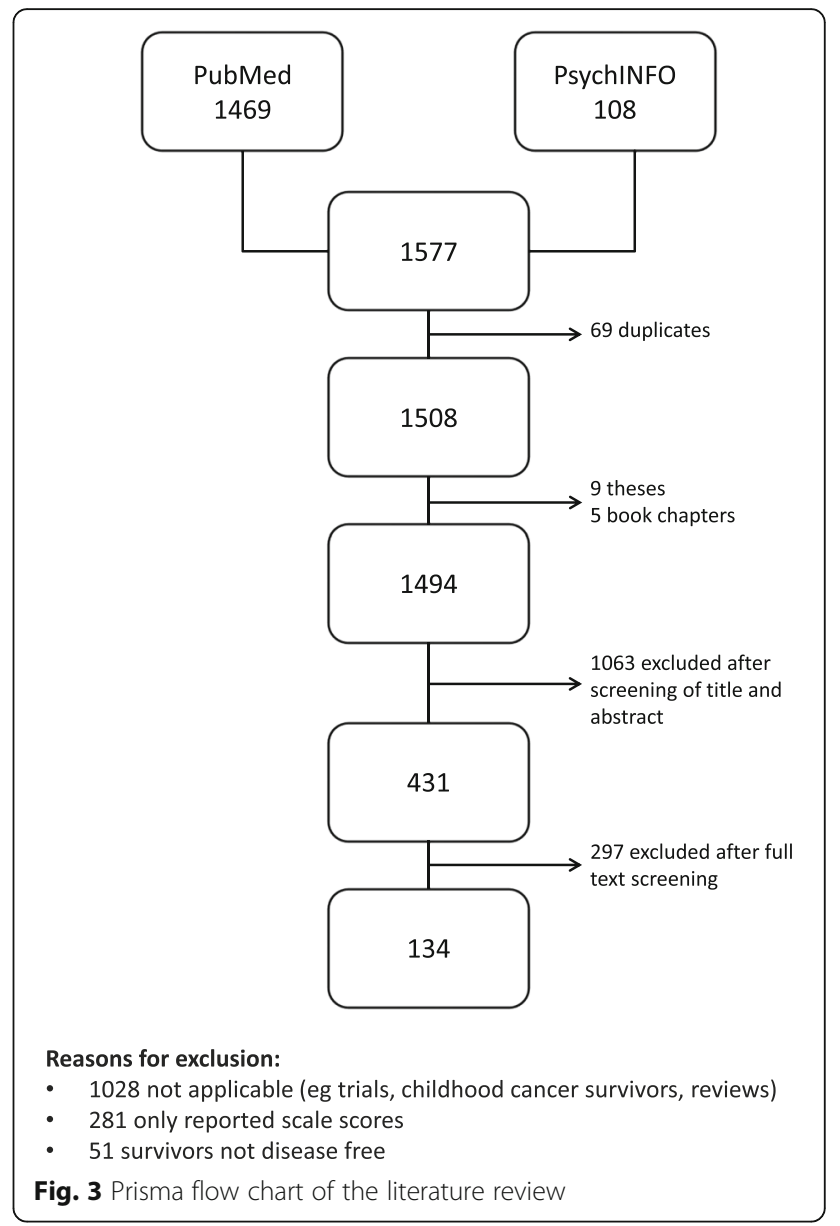

around physical exams" were combined into "fear of recurrence". Issues reflecting states like "being retired" were not included, as they cannot be assessed on a 4-point scale, and would not be informative for an assessment of HRQOL. Issues stating a change in physical symptoms were not included. General issues like "emotional problems" were not included as we believed that they were better captured by more informative issues, for example, "being worried", "fear of dying", "anxiousness", "feeling stressed", "feeling depressed". This resulted in 197 generic, 62 cancer site-specific (e.g. pain during urination), and 8 sex-specific (e.g. feeling less feminine) issues.

\section{Relevance ratings of the EORTC core questionnaire (QLQ-C30)}

The relevance ratings are presented in Fig. 4. The figure shows that the functioning scales were still considered relevant by the survivors, with the perceived relevance increasing with longer time since diagnosis. A number of the symptom items and scales were considered less relevant, especially when more time had passed since diagnosis. Two years after diagnosis, nausea/ vomiting, appetite loss, constipation, and diarrhoea were seldom 
Table 1 Number of cancer survivors per cancer site and per region included in phase $1 \mathrm{a}$ and $1 \mathrm{~b}$

\begin{tabular}{|c|c|c|}
\hline & Phase 1a & Phase $1 b$ \\
\hline \multicolumn{3}{|l|}{ Cancer site } \\
\hline Bladder & 7 & 32 \\
\hline Breast & 17 & 53 \\
\hline Colorectal & 12 & 46 \\
\hline Glioma & 10 & 36 \\
\hline Gynecological & 12 & 49 \\
\hline Head \& neck & 10 & 44 \\
\hline Lung & 8 & 41 \\
\hline Lymphoma & 9 & 38 \\
\hline Melanoma & 11 & 38 \\
\hline Prostate & 11 & 44 \\
\hline Testicular & 10 & 37 \\
\hline Total & 117 & 458 \\
\hline \multicolumn{3}{|l|}{ Region } \\
\hline Northern Europe & 30 & 147 \\
\hline Southern Europe & 46 & 126 \\
\hline English speaking & 13 & 98 \\
\hline Central Europe & 28 & 87 \\
\hline \multicolumn{3}{|l|}{ Time since diagnosis } \\
\hline 0.5 to 2 years & 21 & 111 \\
\hline 2 to 5 years & 63 & 189 \\
\hline more than 5 years & 33 & 158 \\
\hline \multicolumn{3}{|c|}{ Time since completing last treatment ${ }^{a}$} \\
\hline 0.5 to 1 year & - & 72 \\
\hline 1 to 2 years & - & 105 \\
\hline 2 to 5 years & - & 172 \\
\hline more than 5 years & - & 109 \\
\hline
\end{tabular}

For phase $1 \mathrm{~b}$ only, also the number of survivors per time since completion of last treatment category is reported

${ }^{a}$ For phase 1 a only information was available regarding date of diagnosis and date of recurrence

rated as being relevant. The ratings showed that particularly insomnia was considered highly relevant by the survivors less than 2 years after diagnosis and fatigue by the survivors who were less than 5 years since diagnosis.

\section{Phase $1 \mathrm{~b}$ interviews: defining minimal time since treatment completion and issue selection}

Between November 2015 and August 2016, we interviewed 458 survivors from 23 centers in 14 countries for phase $1 \mathrm{~b}$ (Table 1). The mean age of the sample was 59 years, and $46 \%$ was female. Sixty percent had been diagnosed with stage I or II cancer, and $16 \%$ had experienced disease recurrence in the past. The average time since last treatment was 3.6 years (Table 2).
We started our analyses by defining the post-treatment survivorship period in the complete phase $1 \mathrm{~b}$ sample by comparing the three subgroups $(0.5-1$ year, 1 to 2 years, and 2 years or more post-treatment). The following QLQC30 items were rated as being relevant in the 0.5-1 year post-treatment survivors subgroup, but no longer so in the other two TST subgroups: needing to stay in bed or a chair during the day, pain interfering with daily activities, physical condition or treatment interfering with family life and social activities, and physical condition or treatment causing financial difficulties. Scores on the functional and symptom scales of the QLQ-C30 showed an increase in physical, role emotional and social functioning one year after completion of treatment, and a decrease in fatigue (Fig. 5). After this first year these scores tended to stabilize. Based on these findings we decided to employ the one year post-treatment mark as the threshold for recommending transitioning to the use of survivorship measures.

Additionally, the analyses of the QLQ-C30 data showed that the following items were of low relevance to all of the TST survivor subgroups: "Do you have any trouble taking a short walk outside of the house?", "Do you need help with eating, dressing, washing yourself or using the toilet?", and those items assessing appetite, nausea, vomiting, and gastrointestinal symptoms.

For the subsequent selection of issues to be included in the survivorship questionnaire, only the 386 respondents who were at least 1 year post-treatment were included. Table 3 displays the 116 issues that were reported as being relevant by respondents in at least 6 of the diagnostic groups. Thirty-four percent of these consisted of issues covering physical functioning (e.g. pain, neuropathy, muscle cramp), 32\% were mental functioning issues (e.g. body image, anxiety, positive affect), 19\% issues were related to social and role functioning (e.g. sexual problems, feelings of belonging) and 16\% involved general health perceptions (e.g. negative health outlook and health behavior). Of the 116 issues, 106 were not included in the QLQ-C30. Table 3 shows which issues are overlapping with the QLQ-C30, which were identified from the literature, and which from the interviews.

In addition to generic issues, we also identified survivorship issues that were cancer site-specific. On average, 26 (range 7-48) issues were considered as cancer-site specific per diagnostic group. We intend to use these issues for the future development of cancer site-specific survivorship modules. Among these cancer site-specific survivorship issues, we observed the following trends: body image issues were frequently endorsed by bladder, breast, colorectal, and head \& neck cancer survivors. Cognitive functioning problems were rated as highly relevant by glioma, lymphoma, lung, bladder, breast, and head and \& neck cancer 

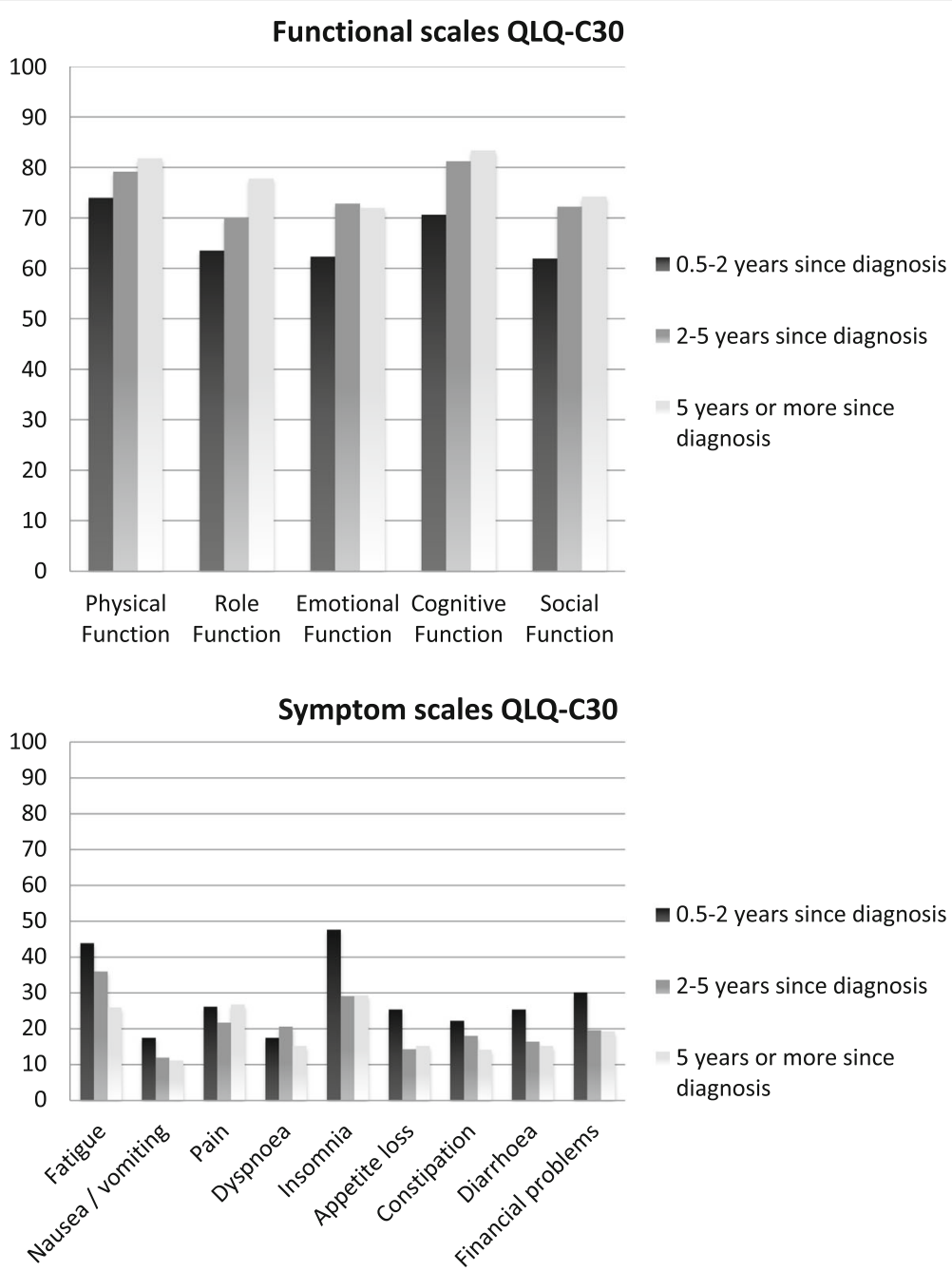

Fig. 4 Relevance ratings of the functional and symptom scales of the QLQ-C30 per time since diagnosis group. The $y$-axis shows the relevance ratings of the QLQ-C30. A higher score on a scale means that the survivors considered the items of a particular scale more relevant

survivors. Lung cancer and glioma survivors reported having a negative health outlook as highly relevant. Bladder and head \& neck cancer survivors frequently endorsed role functioning issues. Lung, lymphoma, and colorectal cancer survivors more often endorsed work-related issues than the other survivor groups. Glioma and lymphoma survivors more frequently rated issues related to a negative impact on feelings of belonging as relevant.

Based on the 94 survivors below the age of 50 years, we identified 10 issues that were relevant for younger survivors and for which relevance declined with age (see Table 3). Three issues were related to body image; the others were related to the ability to have children, being treated differently by people because of having had cancer, difficulties talking about cancer, negative personality change, needing psychological support, loss of future life plans, and financial problems.

\section{Discussion}

In this first phase of our cancer survivorship questionnaire development project, we identified 116 generic survivorship issues. Additionally, on average, we identified 26 site-specific survivorship issues per tumor site, which only partially overlapped with the existing EORTC site-specific modules. We also observed that, approximately one year following completion of cancer treatment, most of the acute disease- and treatment-related symptoms have resolved themselves in the large majority of survivors.

Based on these findings, we will move forward with the development of a core survivorship questionnaire for disease-free adult survivors who are at least one year post-treatment. This questionnaire will retain many of the original items and scales from the QLQ-C30, deleting only those items that assess acute symptoms (nausea/vomiting, appetite loss, constipation, and diarrhea). Additional survivorship issues will be added to expand 
Table 2 Basic demographics, disease and treatment characteristics of the survivors included in phase $1 \mathrm{~b}$

\begin{tabular}{|c|c|c|c|}
\hline \multirow[t]{2}{*}{ Survivors } & \multirow{2}{*}{$\begin{array}{l}\text { Phase 1a } \\
N=117\end{array}$} & \multicolumn{2}{|l|}{ Phase 1b } \\
\hline & & $\begin{array}{l}\text { Total } \\
N=458\end{array}$ & $\begin{array}{l}\text { Subsample } \\
N=386^{\mathrm{a}}\end{array}$ \\
\hline \multicolumn{4}{|l|}{ Age } \\
\hline Mean \pm SD (years) & 57 (13.6) & $59(13.8)$ & $59(13.7)$ \\
\hline \multicolumn{4}{|l|}{ Sex (\%) } \\
\hline male & $58(50 \%)$ & $246(54 \%)$ & 207 (54\%) \\
\hline \multicolumn{4}{|l|}{ Partner status ${ }^{b}$} \\
\hline in relationship & 90 & 367 & 313 \\
\hline $\begin{array}{l}\text { widower/ divorced/ } \\
\text { separated }\end{array}$ & 9 & 61 & 49 \\
\hline single & 14 & 50 & 43 \\
\hline \multicolumn{4}{|l|}{ Education (\%) } \\
\hline $\begin{array}{l}\text { none or primary } \\
\text { school only }\end{array}$ & $15(13 \%)$ & $59(13 \%)$ & $47(12 \%)$ \\
\hline high school & $46(39 \%)$ & 167 (36\%) & $140(36 \%)$ \\
\hline college or university & $53(45 \%)$ & $222(48 \%)$ & $190(49 \%)$ \\
\hline missing & $3(3 \%)$ & $10(2 \%)$ & $9(2 \%)$ \\
\hline \multicolumn{4}{|l|}{ Work status (\%) } \\
\hline working & $59(50 \%)$ & $205(45 \%)$ & $180(47 \%)$ \\
\hline retired & $43(37 \%)$ & $185(40 \%)$ & $157(41 \%)$ \\
\hline unemployed & $4(3 \%)$ & $24(5 \%)$ & $17(4 \%)$ \\
\hline homemaker & $4(3 \%)$ & $22(5 \%)$ & $17(4 \%)$ \\
\hline disabled & $5(4 \%)$ & $10(2 \%)$ & $7(2 \%)$ \\
\hline other or missing & $2(2 \%)$ & $12(2 \%)$ & $10(3 \%)$ \\
\hline Disease recurrence (\%) & $11(9 \%)$ & $75(16 \%)$ & $66(17 \%)$ \\
\hline \multicolumn{4}{|l|}{ Tumor stage ${ }^{c}(\%)$} \\
\hline stage I & $19(16 \%)$ & $101(23 \%)$ & $88(24 \%)$ \\
\hline stage II & 45 (38\%) & $131(30 \%)$ & $108(28 \%)$ \\
\hline stage III & $29(25 \%)$ & $113(25 \%)$ & $95(25 \%)$ \\
\hline stage IV & $3(3 \%)$ & $40(9 \%)$ & $34(9 \%)$ \\
\hline stage unknown & $13(11 \%)$ & $47(11 \%)$ & $40(10 \%)$ \\
\hline no stage determined & $8(7 \%)$ & & \\
\hline \multicolumn{4}{|c|}{ Time since completing primary treatment } \\
\hline Mean (SD) (years) & - & $4.2(4.0)$ & $4.8(4.0)$ \\
\hline \multicolumn{4}{|c|}{ Time since completing last treatment } \\
\hline Mean (SD) (years) & - & $3.6(3.2)$ & $4.4(3.2)$ \\
\hline \multicolumn{4}{|l|}{ Therapy ${ }^{\mathrm{b}}$} \\
\hline surgery & 98 & 342 & 326 \\
\hline chemotherapy & 77 & 254 & 222 \\
\hline radiotherapy & 54 & 238 & 209 \\
\hline hormonal therapy & 15 & 49 & 48 \\
\hline monoclonal antibodies & 2 & 21 & 18 \\
\hline cell transplantation & & 6 & 6 \\
\hline active surveillance & 7 & 66 & 59 \\
\hline
\end{tabular}

Table 2 Basic demographics, disease and treatment characteristics of the survivors included in phase $1 \mathrm{~b}$ (Continued)

\begin{tabular}{|c|c|c|c|}
\hline \multirow[t]{2}{*}{ Survivors } & \multirow{2}{*}{$\begin{array}{l}\text { Phase 1a } \\
N=117\end{array}$} & \multicolumn{2}{|c|}{ Phase 1b } \\
\hline & & $\begin{array}{l}\text { Total } \\
N=458\end{array}$ & $\begin{array}{l}\text { Subsample } \\
N=386^{\mathrm{a}}\end{array}$ \\
\hline $\begin{array}{l}\text { current maintenance } \\
\text { therapy }\end{array}$ & 8 & 61 & 47 \\
\hline \multicolumn{4}{|c|}{ 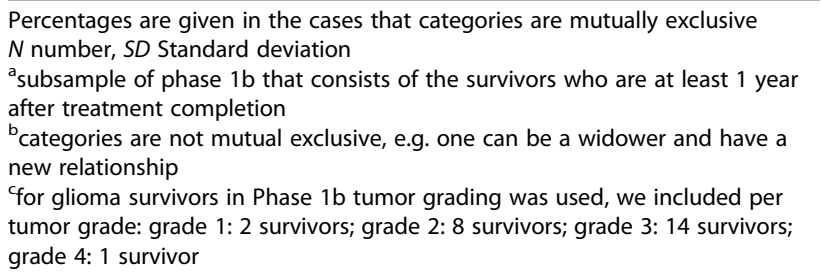 } \\
\hline
\end{tabular}

the scope of issues addressed by the questionnaire. To improve the measurement precision of some of the existing scales of the QLQ-C30, we will collaborate with the EORTC CAT team [42] to select the issues of the generic issue list and the items of the EORTC QLG item library assessing these issues. This survivorship questionnaire can be complemented by cancer-site specific survivorship modules based on and adapted from the existing EORTC cancer site-specific modules.

The period after treatment completion is often described by survivors as more difficult than the treatment itself [43]. The end of the phase of transition from being a patient to resuming normal life [44] can be very positive, but also brings with it feelings of uncertainty about the future and fear of cancer recurrence. During this early survivorship period, patients often begin to process the emotions related to the diagnosis, to find meaning in their experience of having had cancer, and to deal with the lingering effects of treatment. The end of this turbulent immediate post-treatment period appears to represent an appropriate starting point for assessing survivorship issues, as both physical and psychosocial health begin to stabilize. This was corroborated by the increase in physical, role, and social functioning and the decline in fatigue observed in our study sample after the first post-treatment year. We did not observe a further decline in the acute symptoms of cancer treatment, as the prevalence of acute symptoms was already low a half year after treatment completion. The chronic side effects of treatment (pain, dyspnea, insomnia, and fatigue) continued to be relevant for all survivor groups into the longer posttreatment phase.

In accordance with the existing cancer survivorship questionnaires [4-12] our results indicate that feelings of uncertainty about the future, fears related to recurrence of cancer, fears and worries concerning family members, feelings of depression and anger, feelings that others do not understand the impact of cancer, positive impact on social relationships, positive changes in (perception of) 


\section{Functional scales QLQ-C30}

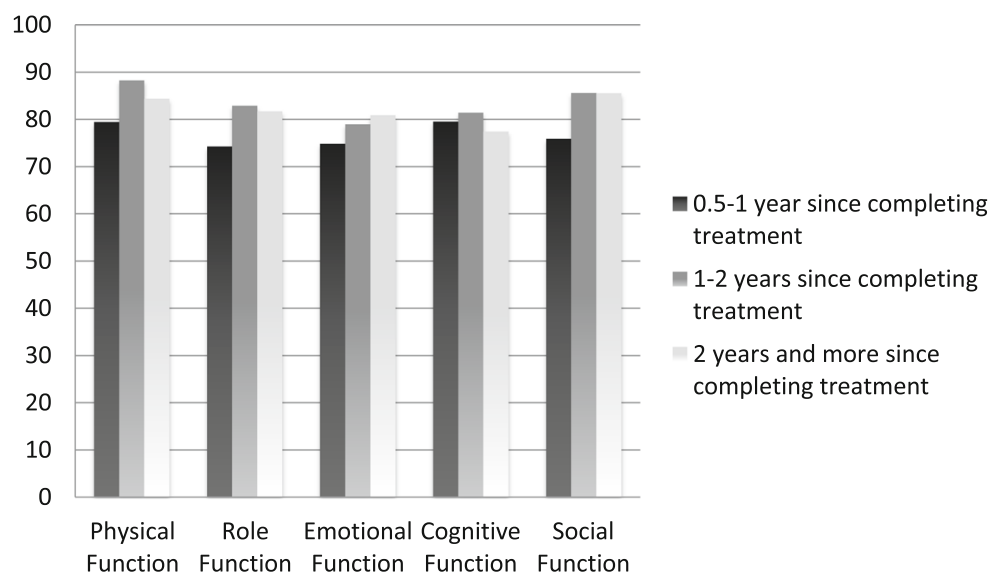

Symptom scales QLQ-C30

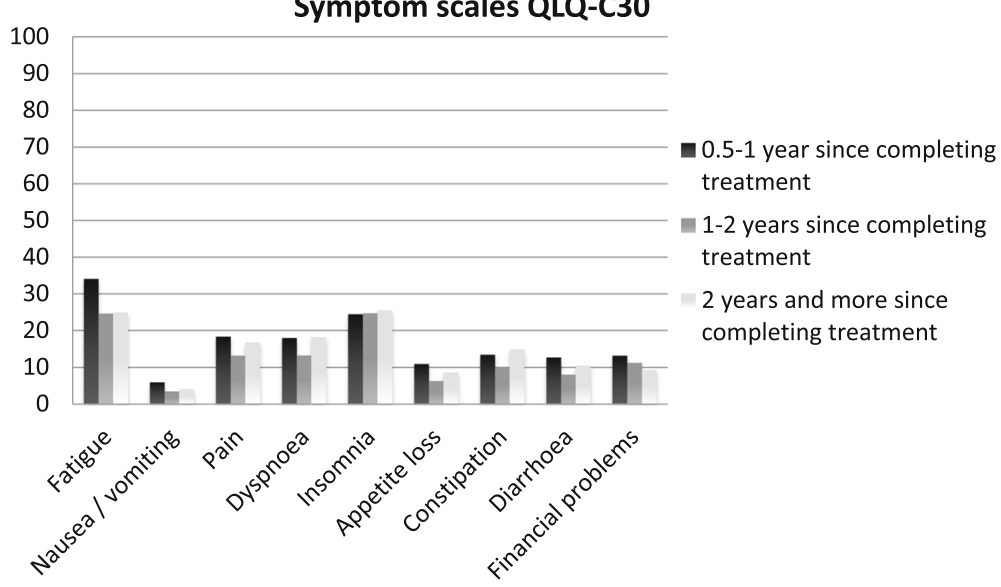

Fig. 5 Functional and symptom scales of the QLQ-C30 per time since last treatment category. The $y$-axis shows the scores on QLQ-C30. On the functional scales a higher score represents a better level of functioning and on the symptom scales a higher score represents a higher level of symptoms

life, negative body image, cognitive problems, fatigue, sleeping problems, pain, sexual problems, and dealing with the chronic physical consequences of cancer are all relevant issues for cancer survivors. However, our results also indicate that other issues often included in survivorship questionnaires may be less relevant when rated by a wider range of cancer survivors in an international context. This includes issues related to feelings of guilt, fears related to starting new (romantic) relationships, and feelings of pride about having survived cancer. Also, compared to existing questionnaires, our findings underscore the relevance of assessing issues related to chronic side effects of treatment such as neuropathy and joint pain [4-12]. Over $30 \%$ of the issues were related to physical functioning, including chronic physical effects of cancer and its treatment, like Raynaud symptoms, neuropathy, joint pain, and muscle cramps. These issues receive relatively little attention in the existing cancer survivorship questionnaires. The differences between our findings and the existing survivorship questionnaires may reflect both culture (including differences between the American and European health care systems) and the fact that we included a wider range of diagnostic groups in our study, and placed relatively less emphasis on breast cancer and non-solid cancer survivors, as has typified the developmental phase of other survivorship questionnaires.

Another important finding from our study is that there is not only a fairly large number of condition-specific physical health issues in cancer survivorship, but also differences in the extent to which various psychosocial issues are perceived as relevant by specific cancer diagnostic groups. These differences in perceived relevance of survivorship issues may reflect differences in survival rates between the cancer types, the average age at diagnosis, the nature of the chronic side effects of the various treatments, and whether a cancer diagnosis is sex-specific. For example, glioma and lung cancer survivors reported issues related to the negative impact of 
Table 3 Consolidated issue list with generic survivorship issues

Body Image

- feeling unattractive ${ }^{b, c}$

- feeling old ${ }^{b}$

- feeling satisfied with your physical appearance ${ }^{b, c}$

- feeling you could not trust your body ${ }^{b, c}$

Cognitive functioning

- difficulties with concentration ${ }^{\mathrm{a}, \mathrm{b}, \mathrm{c}}$

- forgetfulness $s^{b, c}$

- memory problems $s^{a, b, c}$

- problems with multi-tasking ${ }^{\text {b, c }}$

- difficulty gathering your thoughts (together) ${ }^{\mathrm{b}, \mathrm{c}}$

- ability to think (to process information) has slowed down ${ }^{b, c}$

Health behaviors

- being alert for symptoms that may signal a return of my cancer $^{b, c}$

- going quickly to my GP due to having (had) cancer ${ }^{c}$

- drinking less alcohol due to having (had) cancer $^{\text {b, } c}$

- listening to my body due to having (had) cancerb, c

- eating healthily due to having (had) cancer ${ }^{b, c}$

- avoiding the sun or protecting my skin due to having (had) cancer ${ }^{b, c}$

- exercising (more) due to having (had) cancerb, c

- avoiding stress in my life due to having (had) cancer $^{\text {b, c }}$

- cutting down smoking due to having (had) cancer (not applicable option) ${ }^{\mathrm{b}, \mathrm{c}}$

- taking better care of yourself due to having (had) cancer $^{b}$, c

Meaning of cancer

- other issues not related to cancer bother me more than having had cancer ${ }^{b, c}$

- cancer is a learning experience $\mathrm{b}^{\mathrm{b}, \mathrm{c}}$

- having (had) cancer has made me accept my own mortality ${ }^{\mathrm{b}, \mathrm{c}}$

- overall quality of life $e^{a, b, c}$

- being (more) emotional due to having (had) cancer $^{\text {b, } c}$

- seeking a deeper meaning in having (had) cancer $^{\mathrm{b}}$

Negative outlook

- concerned with long term effects of cancer treatment ${ }^{\mathrm{b}, \mathrm{c}}$

- feeling that my life has been suspended because of having (had) cancer ${ }^{\text {b, } c}$

- difficulties adapting my life to the physical consequences of having had cancer ${ }^{b, c}$

- still feeling like a cancer patient ${ }^{b, c}$

- experiencing uncertainty about the future ${ }^{\mathrm{b}, c}$

Positive outlook

- appreciating life (more) due to having (had) cancer $^{b, c}$

- being psychologically strong(er) due to having (had) cancer $^{\text {b, c }}$

- my personality has changed for the better due to having (had) cancer b, c

- having (had) cancer has given me a purpose in life ${ }^{b}$

- because of having (had) cancer I have reconsidered my priorities in life ${ }^{b, c}$

- standing up for myself (more) due to having (had) cancer ${ }^{b, c}$

- having (had) cancer has given me a reason to make changes in my life ${ }^{\text {b, } c}$

- willing to help others (more) due to having (had) cancer ${ }^{b, c}$

- due to having (had) cancer, being (more) understanding of what other people feel ${ }^{b, c}$

Mental health

Depression/behavioral-emotional control

- feeling depressed ${ }^{a}$, b, c

- feeling angry or frustrated ${ }^{b, c}$

- feeling stressed ${ }^{b, c}$

- mood swings $s^{b, c}$

- needing psychological support ${ }^{\mathrm{b}, \mathrm{c}}$

- feeling irritable ${ }^{a, b, c}$

- feeling upset about having (had) cancer ${ }^{\text {b, c }}$

\section{Anxiety}

- being worried ${ }^{a}, b, c$

- feeling anxious ${ }^{b, c}$

Physical symptoms

- altered hair structure ${ }^{b, c}$
Health distress

- fear of recurrence or spread cancer ${ }^{b, c}$

- worried about health ${ }^{\text {b, c }}$

- fear of dying ${ }^{b, c}$

- fear of new cancerb, c

- fear family members will develop cancer ${ }^{\mathrm{b}, \mathrm{c}}$ 
Table 3 Consolidated issue list with generic survivorship issues (Continued)

- weight gain ${ }^{\mathrm{b}, \mathrm{c}}$

- feeling ill or unwell ${ }^{b}$

- acid reflux ${ }^{b}$

- overall health ${ }^{a, b}, c$

Fatigue

- feeling constantly tired ${ }^{b, c}$

- needing more sleep to function ${ }^{c}$

- feeling exhausted ${ }^{b, c}$

- feeling tired ${ }^{a, b}, c$

- needing time to recover from normal activities ${ }^{c}$

- feeling weak ${ }^{a, b}, c$

- needing to take naps ${ }^{b}$

- sudden attacks of tiredness ${ }^{b, c}$

Physical functioning/ mobility

- difficulty carrying something in both hands while climbing stairs ${ }^{b}$

- difficulty taking a long walk $k^{\mathrm{a}, \mathrm{b}, \mathrm{c}}$

- difficulty running fast ${ }^{\mathrm{b}, \mathrm{c}}$

- difficulty carrying something weighing $5 \mathrm{~kg}^{\mathrm{b}, \mathrm{c}}$

- difficulty hiking for $3 \mathrm{~km}^{\mathrm{b}, \mathrm{c}}$

- difficulty walking up a flight of stairs ${ }^{\mathrm{b}, \mathrm{c}}$

- difficulty doing strenuous activities like carrying a heavy shopping bag or a suitcase $^{a, b}$

Pain

- headaches, ${ }^{b, c}$

- joint painc

- muscle pain ${ }^{\mathrm{b}, \mathrm{c}}$

Raynaud

- hands and/or feet sensitive to hot and cold ${ }^{c}$

- cold or pale fingers or toes ${ }^{b, c}$

Muscle problems

- muscle cramps ${ }^{\mathrm{b}, \mathrm{c}}$

- muscle weakness

Role functioning

- limited in recreational activities ${ }^{a, b}, c$

Work

- difficulties returning to work since having (had) cancer ${ }^{b, c}$

- having (had) cancer decreased work performance ${ }^{b, c}$

- career interrupted due to cancer $^{\mathrm{b}, \mathrm{c}}$

Feelings of belonging

Positive impact

- family relationships are close(r) due to having (had) cancer, c

- having (had) cancer has a positive impact on the relationship with my partner ${ }^{b, c}$

- feeling close(r) to friends since having (had) cancer $^{\text {b, c }}$

- friends and family are (more) important since having (had) cancer ${ }^{b, c}$

Sexual problems

- feeling guilty for not fulfilling sexual needs of partner ${ }^{b}$

Sex-specific sexual problems

- vaginal dryness ${ }^{\mathrm{b}, \mathrm{c}}$

- problems getting or maintaining erection ${ }^{b, c}$

Sexual pleasure

- difficulty becoming sexually aroused ${ }^{b}$

- feeling uneasy with sex ${ }^{b}$

- problems enjoying sex ${ }^{\mathrm{b}}$

- problems having an orgasm ${ }^{b}$
Sleep problems

- problems falling asleep ${ }^{b, c}$

- waking up frequently at night ${ }^{b, c}$

- trouble sleeping ${ }^{a, b}$, c

- waking up too early ${ }^{\mathrm{b}}$

Leg problems

- difficulty standing for a long time $e^{b, c}$

- restless legs ${ }^{c}$

- swollen feet or legs $s^{b, c}$

Skin Problems

- dry and or scaly skin ${ }^{b, c}$

- thin skin ${ }^{b, c}$

Neuropathy

- tingling in hands and/or feet ${ }^{\text {b, c }}$

Temperature

- night sweats ${ }^{\text {b, } c}$

- hot flushes ${ }^{b, c}$

- feeling cold ${ }^{b, c}$
Negative impact

- feeling that others do not understand the impact of having (had) cancer $^{\mathrm{b}, \mathrm{c}}$

- not wanting to burden family members ${ }^{b}$ c

- worried about the impact of my cancer on my children ${ }^{b, c}$

Sexual frequency

- low interest in $\operatorname{sex}^{\mathrm{b}, \mathrm{c}}$

- sexually active with or without intercourse ${ }^{b, c}$

- avoiding sex $^{\mathrm{b}}$ 
Table 3 Consolidated issue list with generic survivorship issues (Continued)

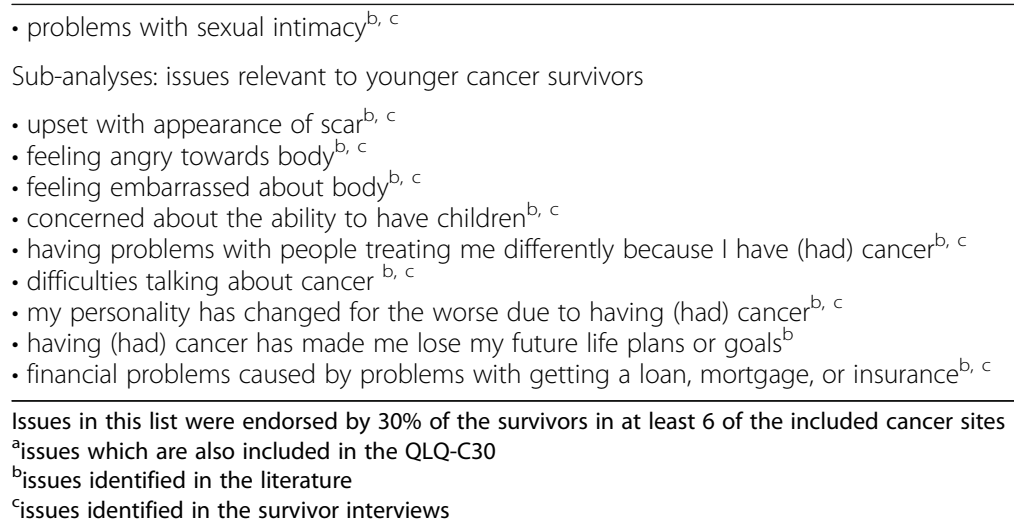

cancer on their lives and issues related to struggles with family and friends as being very relevant; lung, lymphoma, and colorectal cancer survivors more frequently rated work-related issues; and bladder and head \& neck cancer survivors more frequently endorsed role functioning issues. Most of these site-specific survivorship issues are currently not included in the existing site-specific modules of the EORTC.

The literature consistently shows that younger cancer survivors report a higher impact of their cancer experience on HRQOL $[45,46]$, including higher levels of distress, than older cancer survivors. This is likely related to the fact that relatively younger survivors are confronted with a life-threatening illness at a time when many are in the midst of forming relationship bonds, starting and raising families, and trying to establish a workable balance between career and family life. During this period of young adulthood, a serious illness such as cancer is less expected, and may therefore be more disruptive. Also, younger cancer patients and survivors may perceive themselves as having more to lose in terms of future perspective, and may have fewer opportunities for peer support (i.e., having contemporaries with whom they can share their common experience of having had cancer). Conversely older survivors have more life experience, which might lead to better coping strategies, and they may face fewer work-related and social demands. This is supported by the findings from our study that younger survivors are more likely than older survivors to rate issues related to having children, financial difficulties, loss of future life plans, and lack of support as being relevant to them. Although some of these issues appear to be more relevant to younger survivors, in the interest of parsimony (i.e., not having to create two versions of a core survivorship questionnaire), we have decided to include them in our consolidated issue list.

A strength of our study is that we included a relatively large number of survivors from 11 cancer diagnosis groups from a total of 14 European countries. This enhances the generalizability of our findings. Also, our strategy with site-specific survivor modules ensures that relevant chronic physical symptoms are included. Furthermore, the retention of the items and scales of the QLQ-C30 that are still relevant for disease-free survivors will ensure continuity in the evaluation of HRQOL over time, from diagnosis through the long-term survivorship phase.

A possible limitation of our work is that those cancer survivors in our sample who were more than 5 years post-treatment were drawn primarily from hospital registries. Many patients who are 5 years or longer posttreatment may no longer be in active follow-up, and those who are may be those with more serious, chronic health problems. This could cause some degree of overestimation of the relevance of various survivorship issues in this subgroup of longer term survivors. Also, our sample was somewhat younger than one might expect based on the median age of the general population at cancer diagnosis (66 years) [47].

\section{Conclusions}

We identified 116 generic survivorship issues, and on average, 26 site-specific survivorship issues per tumor site. Compared to existing cancer survivorship questionnaires, our findings underscore the relevance of assessing issues related to chronic physical side effects of treatment such as neuropathy and joint pain in addition to the psychosocial aspects of survivorship.

In the next phase of this project, we will further develop and test the core survivorship questionnaire, and we will also develop survivorship modules for breast, prostate, and colorectal cancer survivors. The choice of these three disease sites was based on the incidence, survival rates, and the number of survivorship studies conducted in these disease sites. In the longer term, we intend to develop survivorship modules for a much broader set of cancer sites. Ultimately, this will yield a comprehensive suite of survivorship questionnaires that will yield both a common data set for comparison of results across tumor 
sites, and unique information about the survivorship experience of specific groups of cancer survivors.

\section{Additional file}

Additional file 1: The list of 134 articles included in the review. (PDF $118 \mathrm{~kb}$ )

\section{Abbreviations}

CPILS: Cancer Problems in Living Scale; EORTC: European Organisation for Research and Treatment of Cancer; FACT-G: Functional Assessment of Cancer Therapy - General; HRQOL: Health-related quality of life; IOC/IOCv2: Impact of Cancer; MOS: Medical Outcomes study; N: Number; PROMs: Patientreported outcome measures; QLACS: Quality of Life in Adult Cancer Survivors; QLG: Quality of Life Group; QLQ: Quality of life questionnaire; QLQC30: EORTC core questionnaire; QOL: Quality of life; QoL-CS: Quality of Life Cancer Survivors: SD: Standard deviation; SLDC-C: Satisfaction with Life Domains Scale for Cancer; TST: Time-since-completion-of-last-treatment; WHO: World Health Organization

\section{Funding}

This study was funded by the a grant from the European Organisation for Research and Treatment of Cancer Quality of Life Group (003/2014).

\section{Availability of data and materials}

The data that support the findings of this study are available from the Division of Psychosocial Research and Epidemiology of the Netherlands Cancer Institute (contact person: L.V. van de Poll-Franse), but restrictions apply to the availability of these data due to an agreement between the Netherlands Cancer Institute and the European Organisation for Research and Treatment of Cancer Quality of Life Group, and so they are not publicly available. Data are available pending approval of both the Netherlands Cancer Institute and the EORTC.

\section{Authors' contributions}

Study conception and design: ML, OH, JA, AC, ASD, LD, BH, CJ, OM, JR, JCR, $K T$, IVL, TY, NA, LPF. Acquisition of data: ML, OH, PA, JA, OC, AC, ASD, LD, ME, $\mathrm{EH}, \mathrm{BH}, \mathrm{CJ}, \mathrm{MK}, \mathrm{TK}, \mathrm{OM}, \mathrm{SN}, \mathrm{AN}, \mathrm{AP}, \mathrm{MP}, \mathrm{KP}, J \mathrm{R}, \mathrm{JCR}, \mathrm{SS}, \mathrm{KT}, \mathrm{W}, \mathrm{IVL}$, SV, TY. Analysis and interpretation of data: $M L, O H, N A, L P F$. Drafting of manuscript: ML, NA, LPF. Critical revision: ML, OH, JA, ASD, LD, ME, TK, SN, AN, AP, MP, JR $J C R, K T, I V L, S V, T Y, N A$, LPF. All authors read and approved the final manuscript.

\section{Ethics approval and consent to participate}

The study was approved by the METC-AVL (P16SUR) and has been performed in accordance with the ethical standards as laid down in the 1964 Declaration of Helsinki and its later amendments or comparable ethical standards. Informed consent was obtained from all individual participants included in the study.

\section{Competing interests}

The authors declare that they have no competing interests.

\section{Publisher's Note}

Springer Nature remains neutral with regard to jurisdictional claims in published maps and institutional affiliations.

\section{Author details}

${ }^{1}$ Division of Psychosocial Research \& Epidemiology, The Netherlands Cancer Institute, Amsterdam, The Netherlands. ${ }^{2}$ Department of Medical Psychology, Radboud University Medical Center, Nijmegen, The Netherlands. ${ }^{3}$ Experimental Neurology Unit, School of Medicine and Surgery, University of Milano-Bicocca, Monza, Italy. ${ }^{4}$ Milan Center for Neuroscience, Milan, Italy. ${ }^{5}$ Oncology Departments, Complejo Hospitalario de Navarra, Pamplona, Spain. ${ }^{6}$ Pôle Neurosciences Cliniques, Service de Neuro-Oncologie, Aix-Marseille Université, Marseille, France. ${ }^{7}$ Departmental Psychoncology Unit, Sant'Andrea Hospital, Sapienza University of Rome, Rome, Italy. ${ }^{8}$ Faculty of Health Sciences, University of Southampton, Southampton, UK. 'Department of
}

Neurology, Leiden University Medical Center, Leiden, The Netherlands. ${ }^{10}$ Department of Neurology, Haaglanden Medical Center, The Hague, the Netherlands. ${ }^{11}$ Division of Epidemiology and Health Services Research at Institute of Medical Biostatistics, Epidemiology and Informatics (IMBEI), Mainz, Germany. ${ }^{12}$ Department of Otolaryngology Head and Neck Surgery, Sahlgrenska University Hospital, Göteborg, Sweden. ${ }^{13}$ Department of Psychiatry and Psychotheraphy, Division of Psychooncology, Innsbruck Medical University, Innsbruck, Austria. ${ }^{14}$ University Surgical Unit, University Hospitals Southampton, Southampton, UK. ${ }^{15}$ Department of Nutrition \& Dietetics, School of Health Sciences and Education, Harokopio University, Athens, Greece. ${ }^{16}$ Unit of Survivorship Research, Danish Cancer Society Research Center, Copenhagen, Denmark. ${ }^{17}$ Oncology Institute, Chaim Sheba Medical Center, Tel-Hashomer, Israel. ${ }^{18}$ Department of Psychosomatic Medicine Center for Internal Medicine and Dermatology, Charité Universitätsmedizin Berlin, Berlin, Germany. ${ }^{19}$ East Kent Gynaecological Oncology Centre, Margate, UK. ${ }^{20}$ Neuroncology Unit, National Cancer Institute Regina Elena, Rome, Italy. ${ }^{21}$ Rehabilitation Unit, Department of Supportive Care, Istituto Nazionale Tumori - IRCCS- Fondazione G. Pascale, Naples, Italy. ${ }^{22}$ Evangelische Kliniken Gelsenkirchen, Gelsenkirchen, Germany.

${ }^{23}$ Department of Gastroenterology and Hepatology, Hampshire Hospitals NHS Foundation Trust, Basingstoke, UK. ${ }^{24}$ Department of Neurology and Brain Tumor Center Amsterdam, VU University Medical Center, Amsterdam, The Netherlands. ${ }^{25}$ Unit of Psychoncology - Breast Unit, Istituto Oncologico Veneto (IOV)-IRCCS, Padua, Italy. ${ }^{26}$ Health Outcomes Research Unit, Department of Geriatrics, Gerontology, and Social Work, Faculty of Education, Ignatianum Academy, Krakow, Poland. ${ }^{27}$ Department of Radiation Oncology, Bank of Cyprus Oncology Centre, Nicosia, Cyprus. ${ }^{28}$ Department of Otolaryngology / Head \& Neck Surgery, VU University Medical Center, Amsterdam, The Netherlands. ${ }^{29}$ Department of Gynecology and Obstetrics, Sorlandet Hospital Kristiansand, Kristiansand, Norway. ${ }^{30}$ Lynda Jackson Macmillan Centre, East \& North Hertfordshire NHS Trust including Mount Vernon Cancer Centre, Northwood, UK. ${ }^{31}$ Comprehensive Cancer Centre South (CCCS), Eindhoven Cancer Registry, Eindhoven, The Netherlands.

${ }^{32}$ Tilburg University, Tilburg, The Netherlands.

Received: 20 December 2017 Accepted: 30 April 2018

Published online: 04 June 2018

\section{References}

1. Ayanian JZ, Jacobsen PB. Enhancing research on cancer survivors. J Clin Oncol Off J Am Soc Clin Oncol. 2006:24:5149-53.

2. Aaronson NK, Ahmedzai S, Bergman B, Bullinger M, Cull A, Duez NJ, Filiberti A, Flechtner H, Fleishman SB, De Haes JC. The European Organization for Research and Treatment of Cancer QLQ-C30: a qualityof-life instrument for use in international clinical trials in oncology. J Natl Cancer Inst. 1993:85:365-76.

3. Cella DF, Tulsky DS, Gray G, Sarafian B, Linn E, Bonomi A, Silberman M, Yellen SB, Winicour $P$, Brannon J. The functional assessment of cancer therapy scale: development and validation of the general measure. J Clin Oncol. 1993:11:570-9.

4. Zhao L, Portier K, Stein K, Baker F, Smith T. Exploratory factor analysis of the cancer problems in living scale: a report from the American Cancer Society's studies of cancer survivors. J Pain Symptom Manag. 2009;37:676-86.

5. Baker F, Denniston M, Zabora JR, Marcellus D. Cancer problems in living and quality of life after bone marrow transplantation. J Clin Psychol Med Settings. 2003;10:27

6. Zebrack BJ, Ganz PA, Bernaards CA, Petersen L, Abraham L. Assessing the impact of cancer: development of a new instrument for long-term survivors. Psychooncology. 2006:15:407-21.

7. Crespi CM, Ganz PA, Petersen L, Castillo A, Caan B. Refinement and psychometric evaluation of the impact of cancer scale. J Natl Cancer Inst. 2008;100:1530-41

8. Crespi CM, Ganz PA, Petersen L, Smith SK. A procedure for obtaining impact of cancer version 2 scores using version 1 responses. Qual Life Res. 2013;22:103-9.

9. Avis NE, Ip E, Foley KL. Evaluation of the quality of life in adult cancer survivors (QLACS) scale for long-term cancer survivors in a sample of breast cancer survivors. Health Qual Life Outcomes. 2006:4:92

10. Avis NE, Smith KW, McGraw S, Smith RG, Petronis VM, Carver CS. Assessing quality of life in adult cancer survivors (QLACS). Qual Life Res. 2005; 14:1007-23. 
11. Ferrell BR, Dow KH, Grant M. Measurement of the quality of life in cancer survivors. Qual Life Res. 1995;4:523-31.

12. Baker F, Denniston M, Hann D, Gesme D, Reding DJ, Flynn T, Kennedy JS. Factor structure and concurrent validity of the satisfaction with life domains scale for Cancer (SLDS-C). J Psychosoc Oncol. 2007;25:1-17.

13. Muzzatti B, Annunziata MA. Assessing quality of life in long-term cancer survivors: a review of available tools. Support Care Cancer. 2013;21:3143-52.

14. Marzorati C, Riva S, Pravettoni G. Who is a cancer survivor? A systematic review of published definitions. J Cancer Educ. 2017;32:228-37.

15. Stewart AL, Ware JE, Jr. Measuring functioning and well-being: the medical outcomes study approach. Durham and London: Duke University Press; 1992.

16. Johnson C, Aaronson N, Blazeby JM, Bottomley A, Fayers P, Koller M, Kuliś D, Ramage G, Sprangers M, Velikova G, Young T: Guidelines for developing questionnaire modules. 2011.

17. Kumthekar P, Raizer J, Singh S. Low-grade glioma. Cancer Treat Res. 2015; 163:75-87.

18. Charlson ME, Pompei P, Ales KL, Mackenzie CR. A new method of classifying prognostic comorbidity in longitudinal studies: development and validation. J Chronic Dis. 1987;40:373-83.

19. Van Andel G, Bottomley A, Fosså SD, Efficace F, Coens C, Guerif S, Kynaston H, Gontero P, Thalmann G, Akdas A, et al. An international field study of the EORTC QLQ-PR25: a questionnaire for assessing the health-related quality of life of patients with prostate cancer. Eur J Cancer. 2008;44:2418-24.

20. Greimel E, Bottomley A, Cull A, Waldenstrom AC, Arraras J, Chauvenet L, Holzner B, Kuljanic K, Lebrec J, D'Haese S. An international field study of the reliability and validity of a disease-specific questionnaire module (the QLQOV28) in assessing the quality of life of patients with ovarian cancer. Eur J Cancer. 2003;39:1402-8.

21. Greimel E, Nordin A, Lanceley A, Creutzberg CL, van de Poll-Franse LV, Radisic VB, Galalae R, Schmalz C, Barlow E, Jensen PT, et al. Psychometric validation of the European organisation for research and treatment of cancer quality of life questionnaire-endometrial cancer module (EORTC QLQ-EN24). Eur J Cancer. 2011;47:183-90.

22. Greimel ER, Kuljanic Vlasic K, Waldenstrom AC, Duric VM, Jensen PT, Singer S, Chie W, Nordin A, Bjelic Radisic V, Wydra D. The European Organization for Research and Treatment of Cancer (EORTC) quality-of-life questionnaire cervical cancer module: EORTC QLQ-CX24. Cancer. 2006;107:1812-22.

23. Holzner B, Efficace F, Basso U, Johnson CD, Aaronson NK, Arraras Jl, Smith AB, Chow E, Oberguggenberger AS, Bottomley A, et al. Cross-cultural development of an EORTC questionnaire to assess health-related quality of life in patients with testicular cancer: the EORTC QLQ-TC26. Qual Life Res. 2013;22:369-78.

24. Sprangers MA, Groenvold M, Arraras II, Franklin J, te Velde A, Muller M, Franzini L, Williams A, de Haes HC, Hopwood P, et al. The European Organization for Research and Treatment of Cancer breast cancer-specific quality-of-life questionnaire module: first results from a three-country field study. J Clin Oncol. 1996;14:2756-68.

25. Taphoorn MJ, Claassens L, Aaronson NK, Coens C, Mauer M, Osoba D, Stupp R, Mirimanoff RO, van den Bent MJ, Bottomley A. An international validation study of the EORTC brain cancer module (EORTC QLQ-BN20) for assessing health-related quality of life and symptoms in brain cancer patients. Eur J Cancer. 2010;46:1033-40.

26. Whistance RN, Conroy T, Chie W, Costantini A, Sezer O, Koller M, Johnson $C D$, Pilkington SA, Arraras J, Ben Josef E, et al. Clinical and psychometric validation of the EORTC QLQ-CR29 questionnaire module to assess health-related quality of life in patients with colorectal cancer. Eur J Cancer. 2009:45:3017-26.

27. Bjordal K, De Graeff A, Fayers PM, Hammerlid E, Van Pottelsberghe C, Curran D, Ahlner-Elmqvist M, Maher EJ, Meyza JW, Brédart A, et al. A 12 country field study of the EORTC QLQ-C30 (version 3.0) and the head and neck cancer specific module (EORTC QLQ-H\&N35) in head and neck patients. Eur J Cancer. 2000;36:1796-807.

28. Bergman B, Aaronson NK, Ahmedzai S, Kaasa S, Sullivan M. The EORTC QLQLC13: a modular supplement to the EORTC Core quality of life questionnaire (QLQ-C30) for use in lung cancer clinical trials. EORTC study group on quality of life. Eur J Cancer. 1994;30a:635-42.

29. Blazeby JM, Hall E, Aaronson NK, Lloyd L, Waters R, Kelly JD, Fayers P. Validation and reliability testing of the EORTC QLQ-NMIBC24 questionnaire module to assess patient-reported outcomes in non-muscle-invasive bladder cancer. Eur Urol. 2014;66:1148-56.

30. Efficace F, Baccarani M, Breccia M, Saussele S, Abel G, Caocci G, Guilhot F, Cocks K, Naeem A, Sprangers M, et al. International development of an EORTC questionnaire for assessing health-related quality of life in chronic myeloid leukemia patients: the EORTC QLQ-CML24. Qual Life Res. 2014;23:825-36.

31. van de Poll-Franse L, Oerlemans S, Bredart A, Kyriakou C, Sztankay M, Pallua S, Daniels L, Creutzberg CL, Cocks K, Malak S, et al. International development of four EORTC disease-specific quality of life questionnaires for patients with Hodgkin lymphoma, high- and low-grade non-Hodgkin lymphoma and chronic lymphocytic leukaemia. Qual Life Res. 2018;27:333-45.

32. Cocks K, Cohen D, Wisloff F, Sezer O, Lee S, Hippe E, Gimsing P, Turesson I, Hajek R, Smith A, et al. An international field study of the reliability and validity of a disease-specific questionnaire module (the QLQ-MY20) in assessing the quality of life of patients with multiple myeloma. Eur I Cancer. 2007:43:1670-8.

33. Fereday J, Muir-Cochrane E. Demonstrating rigor using thematic analysis: a hybrid approach of inductive and deductive coding and theme development. Int J Qual Methods. 2006;5:80-92.

34. NVivo qualitative data analysis Software. 10th ed. QSR International Pty Ltd.; 2012.

35. Knobf MT. Reproductive and hormonal sequelae of chemotherapy in women. Premature menopause and impaired fertility can result, effects that are especially disturbing to young women. Am J Nurs. 2006;106:60-5.

36. Kroenke CH, Rosner B, Chen WY, Kawachi I, Colditz GA, Holmes MD. Functional impact of breast cancer by age at diagnosis. J Clin Oncol. 2004;22:1849-56.

37. Wenzel LB, Fairclough DL, Brady MJ, Cella D, Garrett KM, Kluhsman BC Crane LA, Marcus AC. Age-related differences in the quality of life of breast carcinoma patients after treatment. Cancer. 1999;86:1768-74.

38. Norton T, Manne S, Rubin S, Hernandez E, Carlson J, Bergman C, Rosenblum N. Ovarian Cancer Patients' psychological distress: the role of physical impairment, perceived unsupportive family and friend behaviors, perceived control, and self-esteem. Health Psychol. 2005;24:143-52.

39. Bodurka-Bevers D, Basen-Engquist K, Carmack CL, Fitzgerald MA, Wolf JK, De Moor C, Gershenson DM. Depression, anxiety, and quality of life in patients with epithelial ovarian cancer. Gynecol Oncol. 2000;78:302-8.

40. Fitch M, Gray RE, Franssen E. Perspectives on living with ovarian cancer: young women's views. Can Oncol Nurs J. 2000;10:101-8.

41. Stanton AL. What happens now? Psychosocial care for cancer survivors after medical treatment completion. J Clin Oncol. 2012;30:1215-20.

42. Petersen MA, Groenvold M, Aaronson NK, Chie WC, Conroy T, Costantini A, Fayers P, Helbostad J, Holzner B, Kaasa S, et al. Development of computerised adaptive testing (CAT) for the EORTC QLQ-C30 dimensions general approach and initial results for physical functioning. Eur J Cancer. 2010;46:1352-8.

43. Mayer DK, Nasso SF, Earp JA. Defining cancer survivors, their needs, and perspectives on survivorship health care in the USA. Lancet Oncol. 2017;18:e11-8.

44. Stanton AL, Ganz PA, Rowland JH, Meyerowitz BE, Krupnick JL, Sears SR. Promoting adjustment after treatment for cancer. Cancer. 2005;104:2608-13.

45. van der Poel MW, Oerlemans S, Schouten HC, Mols F, Pruijt JF, Maas H, van de Poll-Franse LV. Quality of life more impaired in younger than in older diffuse large B cell lymphoma survivors compared to a normative population: a study from the population-based PROFILES registry. Ann Hematol. 2014:93:811-9.

46. van der Poel MW, Oerlemans S, Schouten HC, van de Poll-Franse LV. Elderly multiple myeloma patients experience less deterioration in health-related quality of life than younger patients compared to a normative population: a study from the population-based PROFILES registry. Ann Hematol. 2015;94:651-61.

47. SEER Cancer Statistics Review, 1975-2014. Bethesda: National Cancer Institute; 2016 